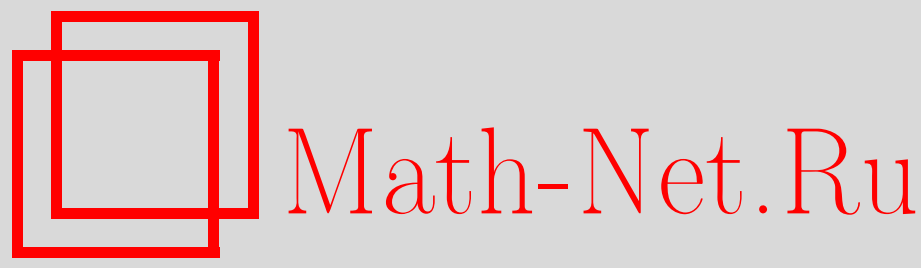

E. Mordecki, Necessary conditions for stable convergence of semimartingales, Теория вероятн. и ее примен., 1999, том 44, выпуск 1, 229-232

DOI: https://doi.org/10.4213/tvp621

Использование Общероссийского математического портала MathNet.Ru подразумевает, что вы прочитали и согласны с пользовательским соглашением

http://www . mathnet.ru/rus/agreement

Параметры загрузки:

IP : 54.237 .59 .107

26 апреля 2023 г., 04:07:50

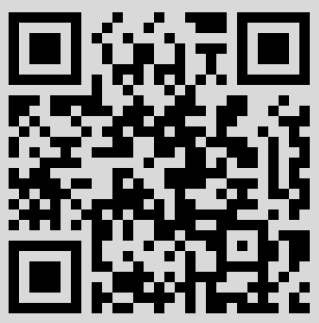




\title{
REFERENCES
}

1. Barndorff-Nielsen O.E. Information and Exponential Families in Statistical Theory. Chichester: Wiley, 1978.

2. Barndorff-Nielsen O.E. Parametric statistical models and likelihood. Lect. Notes in Statist., v. 50, 1988.

3. Barndorff-Nielsen O.E., Blasild P. Exponential models with affine dual foliations. Ann. Statist., 1983, v. 11, p. 753-769.

4. Barndorff-Nielsen O.E., Cox D.R. Inference and Asymptotics. London: Chapman and Hall, 1994.

5. Barndorff-Nielsen O.E., Jupp P.E. Differential geometry, profile likelihood, L-sufficiency and composite transformation models. - Ann. Statist., 1988, v. 16, p. 10091043.

6. Rémon $M$. On a concept of partial sufficiency: $L$-sufficiency. - Internat. Statist. Rev., 1984 , v. 52 , p. $127-136$.

\section{NECESSARY CONDITIONS FOR STABLE CONVERGENCE OF SEMIMARTINGALES}

\begin{abstract}
В статье доказан результат обратной теореме об устойчивой сходимости семимартингалов, полученный в [1]. Как следствие утверждается (при условии некоторого контроля за скачками), что последовательность мартингалов $X^{n}$ устойчиво сходится к непрерывному мартингалу $X$ с условно независимыми приращениями тогда и только тогда, когда квадратичные отклонения $X^{n}$ сходятся по вероятности к квадратичному отклонению $X$ для каждого $t \in \mathbf{R}^{+}$.
\end{abstract}

Ключевые слова и фразы: семимартингал, устойчивая сходимость, независимые приращения.

1. Introduction and results. The subject of the present paper is the characterization of the behaviour of a sequence of semimartingales when they converge stably to a continuous semimartingale with conditionally independent increments. In view of the results due to [3], and more recently to [1], it remains only to prove some inverse theorems, and this is done, based on the extension of existing results for weak convergence, and a convenient characterization of stable convergence. The results presented here were announced in [4].

For general concepts about semimartingales and their characteristics we refer to ([2, Chapters I, II]).

Let us now define the sequence of semimartingales and the limit.

Let $h$ denote a truncation function, and all the characterictics will be considered with respect to $h$.

(S) Consider for each $n \in \mathbf{N}$ a d-dimensional semimartingale $X^{n}$ defined on a stochastic basis $\mathscr{B}^{n}=\left(\Omega, \mathscr{F}, \mathbb{F}^{n}, \mathbf{P}\right)$, with $\mathbb{F}^{n}=\left(\mathscr{F}_{t}^{n}: t \geqslant 0\right)$. Denote by $\left(B^{n}, \widetilde{C}^{n}, \nu^{n}\right)$ the triplet of modified characteristics of $X^{n}$ under $\mathbf{P}$, and by $\left[X^{n}, X^{n}\right]$ the $\mathbf{R}^{d} \otimes \mathbf{R}^{d}$ valued processes whose components are the (co-)quadratic variation $\left[X^{n, j}, X^{n, k}\right]$. Set for simplicity $X_{0}^{n}=0$.

As for the limit consider a transition probability $\mathbf{Q}(\omega, d \gamma)$ from $(\Omega, \mathscr{F})$ into the Skorokhod space

$$
\left(\mathbf{D}\left(\mathbf{R}^{d}\right), \mathscr{D}\left(\mathbf{R}^{d}\right),\left(\mathscr{D}_{t}: t \geqslant 0\right)\right),
$$

\footnotetext{
* Universidad de la República, Montevideo, Uruguay.
} 
such that for each $\omega \in \Omega$ the canonical process on $\mathbf{D}\left(\mathbf{R}^{d}\right)$ defined by $X_{t}(\gamma)=\gamma_{t}$ is a semimartingale with independent increments, and characteristics $(B(\omega), C(\omega), 0)$.

Now we set

$$
\begin{array}{cl}
\bar{\Omega}=\Omega \times \mathbf{D}\left(\mathbf{R}^{d}\right), & \overline{\mathscr{F}}=\mathscr{F} \otimes \mathscr{D}\left(\mathbf{R}^{d}\right), \\
\overline{\mathbf{P}}(d \omega, d \gamma)=\mathbf{P}(d \omega) \mathbf{Q}(\omega, d \gamma), & \overline{\mathbb{F}}=\left(\cap_{s>t}\left(\mathscr{F} \otimes \mathscr{D}_{s}\right): t \geqslant 0\right),
\end{array}
$$

and every process, variable or $\sigma$-field defined on $(\Omega, \mathscr{F})$ or $\left(\mathbf{D}\left(\mathbf{R}^{d}\right), \mathscr{D}\left(\mathbf{R}^{d}\right)\right)$ is naturally extended to $(\bar{\Omega}, \bar{F})$ with the same symbol, e.g., $X(\omega, \gamma)=X(\gamma), X^{n}(\omega, \gamma)=X^{n}(\omega)$, etc.

(L) Let then $X$ be a process defined on $(\bar{\Omega}, \bar{F}, \bar{F}, \overline{\mathbf{P}})$ with $(B, C, 0)$ as characteristics, that is, a process with $\mathscr{F}$-conditionally independent increments. Denote by $[X, X]$ the quadratıc variation of $X$ (defined as above), and observe that $\widetilde{C}=C$

(N) (Nesting condition.) Assume there exısts a sequence of real numbers $\left(\alpha_{n}\right)$ decreasing to 0 , such that

(1) $\mathscr{F}_{\alpha_{n}}^{n} \subset \mathscr{F}_{\alpha_{n+1}}^{n+1}$

(2) $\mathscr{F}=\bigvee_{n} \mathscr{F}_{\alpha_{n}}^{n}$.

Then consider the conditions:

$$
\begin{aligned}
& {\left[\gamma-\mathbf{R}^{+}\right]: \widetilde{C}_{t}^{n} \stackrel{\mathbf{P}}{\longrightarrow} C_{t} \quad \forall t \in \mathbf{R},} \\
& {\left[\delta-\mathbf{R}^{+}\right]: \mathbb{I}_{\{|x|>\varepsilon\}} * \nu_{t}^{n} \stackrel{\mathbf{P}}{\longrightarrow} 0 \quad \forall t \in \mathbf{R} \forall \varepsilon>0 .}
\end{aligned}
$$

Denote $\operatorname{Var}\left(B^{n}\right)_{t}=\sum_{t=1}^{d} \operatorname{Var}\left(B^{n, 2}\right)_{t}$, where $\operatorname{Var}(A)_{t}$ stands for the total variation of a function $A$ on $[0, t]$.

We will say that the sequence $X^{n}$ converges $\mathscr{F}$-stably to $X$ in $\mathbf{D}\left(\mathbf{R}^{d}\right)$ (denoted by $X^{n} \stackrel{\mathrm{d}}{\longrightarrow} X(\mathscr{F}$-stably $\left.)\right)$, if $\mathbf{E}\left(Y f\left(X^{n}\right)\right) \longrightarrow \mathbf{E}(Y f(X))$ as $n \rightarrow+\infty$ for all bounded and $\mathscr{F}$-measurable random variables $Y$ and continuous and bounded functions $f: \mathbf{D}\left(\mathbf{R}^{d}\right) \rightarrow \mathbf{R}$

Theorem 1. Assume conditions (S) and (L) are fulfilled. If

(i) $X^{n} \stackrel{\mathrm{d}}{\longrightarrow} X \quad(\mathscr{F}$-stably $)$,

(ii) $\left(\operatorname{Var}\left(B^{n}\right)_{t} \mid \overline{\mathbf{P}}\right)$ is tıght for all $t \geqslant 0$, then

$$
\left(\left[X^{n}, X^{n}\right], X^{n}\right) \stackrel{\mathrm{d}}{\longrightarrow}([X, X], X) \quad(\mathscr{F} \text {-stably })
$$

and, in partıcular,

$$
\left[X^{n}, X^{n}\right] \stackrel{\mathrm{d}}{\longrightarrow}[X, X] \quad(\mathscr{F}-\text { stably }) .
$$

Corollary 1. Under the assumptions of Theorem $1\left[X^{n}, X^{n}\right]_{t} \stackrel{\mathbf{P}}{\longrightarrow} C_{t} \forall t \geqslant 0$.

Theorem 2. Assume conditions $(\mathrm{S})$ and $(\mathrm{L})$ are fulfilled. If

(i) $X^{n} \stackrel{\mathrm{d}}{\longrightarrow} X \quad(\mathscr{F}$-stably $)$,

then

(ii) $\left(\operatorname{Var}\left(B^{n}\right)_{t} \mid \overline{\mathbf{P}}\right)$ ıs tıght;

(1) $\left[\delta-\mathbf{R}^{+}\right]: \mathbb{I}_{\{|x|>\varepsilon\}} * \nu_{t}^{n} \stackrel{\mathbf{P}}{\longrightarrow} 0 \quad \forall t \in \mathbf{R}^{+} \forall \varepsilon>0$,

(2) $\left[\gamma-\mathbf{R}^{+}\right]: \widetilde{C}_{t}^{n} \stackrel{\mathbf{P}}{\longrightarrow} C_{t} \quad \forall t \in \mathbf{R}^{+}$.

Corollary 2. Assume conditıons (S), (L), and (N) are fulfilled. Suppose that $X^{n}$ 's are local martıngales satısfyıng $\left|\Delta X_{t}^{n}\right| \leqslant c$ for some constant $c$, and $X$ is a contınuous $\mathscr{F}$-conditionally Gaussian martıngale (for each fixed $\omega, X$ is a Gaussian martıngale)

Then the following statements are equivalent:

(1) $X^{n} \stackrel{\mathrm{d}}{\longrightarrow} X \quad(\mathscr{F}$-stably),

(2) $\left[X^{n}, X^{n}\right]_{t} \stackrel{\mathbf{P}}{\longrightarrow}[X, X]_{t} \quad \forall t \in \mathbf{R}^{+}$,

(3) $\left[\gamma-\mathbf{R}^{+}\right]+\left[\delta-\mathbf{R}^{+}\right]$.

2. Proofs. Let us first characterize stable convergence in a convenient way. Let $\mathscr{G}$ be a sub- $\sigma$-field of $\mathscr{F}$. Denote by $\mathscr{P}(\mathscr{G})$ the set of probability measures $\widetilde{\mathbf{P}}$ on $(\Omega, \mathscr{F})$ such that $d \widetilde{\mathbf{P}}=Y d \mathbf{P}$ for any $\mathscr{G}$-measurable, positive and bounded random variable $Y$. Given $X$ a random variable, let $\sigma(X)$ denote the $\sigma$-field generated by $X$. 
Lemma 1. Suppose on a probability space $(\Omega, \mathscr{F}, \mathbf{P})$ a sequence of random elements $X^{n}$ and $X$ with values in a metric space $(E, \delta)$ is given. Let $\mathscr{G} \subset \mathscr{F}$. Then (1) and (2) are equivalent:

(1) $X^{n} \stackrel{\mathrm{d}}{\longrightarrow} X \quad(\mathscr{G}-$ stably $)$,

(2) $\quad X^{n} \stackrel{\mathscr{L}(\widetilde{\mathbf{P}})}{\longrightarrow} X \quad \forall \widetilde{\mathbf{P}} \in \mathscr{P}(\mathscr{G})$.

If $E=\mathbf{R}^{d}, \delta$ is the Euclidean metric in $\mathbf{R}^{d}$, and $\sigma(X) \subset \mathscr{G}$, then (1) or (2) are equivalent to (3):

(3) $X^{n} \stackrel{\mathbf{P}}{\longrightarrow} X$.

$\mathrm{P}$ r o o f. Equivalence (1) $\Leftrightarrow$ (2) follows from linearity and normalization.

$(1) \Rightarrow(3)$. We know that $\mathbf{E}\left(\exp \left\{i\left(\lambda X+\mu X^{n}\right)\right\}\right) \rightarrow \mathbf{E}(\exp \{i(\lambda X+\mu X)\})$ for the real and continuous functions $\cos (\lambda x), \cos (\mu x), \sin (\lambda x), \sin (\mu x)$ and the bounded and $\mathscr{G}$-measurable random variables $\cos (\lambda X), \cos (\mu X), \sin (\lambda X), \sin (\mu X)$.

From this fact it follows that

$$
\left(X, X^{n}\right) \stackrel{\mathscr{L}(\mathbf{P})}{\longrightarrow}(X, X) \text { and } X^{n}-X \stackrel{\mathbf{P}}{\longrightarrow} 0 .
$$

$(3) \Rightarrow(2)$. If $\widetilde{\mathbf{P}} \in \mathscr{P}$ then $\mathbf{P} \sim \widetilde{\mathbf{P}}$. So $X^{n} \stackrel{\widetilde{\mathbf{P}}}{\longrightarrow} X$ and $X^{n} \stackrel{\mathscr{L}(\widetilde{\mathbf{P}})}{\longrightarrow} X$.

$\mathrm{P}$ r o of of $\mathrm{Th}$ e o r e m 1. According to Lemma 1, it suffices to verify

$$
\left(\left[X^{n}, X^{n}\right], X^{n}\right) \stackrel{\mathscr{L}(\widetilde{\mathbf{P}})}{\longrightarrow}([X, X], X),
$$

where $\widetilde{\mathbf{P}} \in \mathscr{P}$.

We know that the quadratic variation is invariant under an absolutely continuous change of measure, so it is natural to apply Theorem VI.6.1 of [2] under $\widetilde{\mathbf{P}}$. Let us verify its hypothesis. We know $X^{n} \stackrel{\mathscr{L}(\widetilde{\mathbf{P}})}{\longrightarrow} X((1) \Rightarrow(2)$ in Lemma 1$)$. In order to prove $\left(\operatorname{Var}\left(B^{n}\right)_{t} \mid \widetilde{\mathbf{P}}\right)$ is tight, let us fix an $\varepsilon>0$. As $\widetilde{\mathbf{P}} \sim \overline{\mathbf{P}}$, there exists a $\delta>0$ such that $\overline{\mathbf{P}}(A)<\delta \Rightarrow \widetilde{\mathbf{P}}(A)<\varepsilon, A \in \mathscr{F}$. Let $K_{\varepsilon}$ be such that $\overline{\mathbf{P}}\left(\operatorname{Var}\left(B^{n}\right)_{t}>K_{\varepsilon}\right)<\delta \forall n \in \mathbf{N}$, then

$$
\widetilde{\mathbf{P}}\left(\operatorname{Var}\left(B^{n}\right)_{t}>K_{\varepsilon}\right)<\varepsilon \quad \forall n \in \mathbf{N} .
$$

Now the application of Theorem VI.6.1 of [2] completes the proof

$$
\left(\left[X^{n}, X^{n}\right], X^{n}\right) \stackrel{\mathscr{L}(\tilde{\mathbf{P}})}{\longrightarrow}([X, X], X) .
$$

$\mathrm{P}$ r o of of $\mathrm{C}$ o r o ll a r y 1 . In view of Theorem 1 and implication (1) $\Rightarrow$ (3) in Lemma 1 the result follows from the fact that $C_{t}$ is $\mathscr{F}$-measurable.

$\mathrm{Pr}$ o of of $\mathrm{Th}$ e or e m 2. (1) As $X$ is continuous,

$$
\sup _{s \leqslant t}\left|\Delta X_{s}^{n}\right| \stackrel{\mathbf{P}}{\longrightarrow} 0
$$

which is equivalent to $\left[\delta-\mathbf{R}^{+}\right]$in virtue of the Lenglart-Rebolledo inequalities (see [2, Section VI.4.22]).

(2) Let $X^{n}=M^{n}+B^{n}+\check{X}^{n}(h)$ be the semimartingale decomposition of $X^{n}$ :

$\check{X}^{n}(h)=\sum_{s \leqslant t} \Delta X_{s}^{n}-h\left(\Delta X_{s}^{n}\right)$,

$M^{n}$ is a local martingale with bounded jumps and $M_{0}^{n}=0$,

$B^{n}$ is a predictable process with finite variation in intervals.

By (2.1) we know $\mathbf{P}\left(\sup _{s \leqslant t}\left|\check{X}^{n}(h)_{s}\right|>0\right) \rightarrow 0$. Furthermore, on the set $\left\{\sup _{s \leqslant t}\left|\Delta \check{X}_{s}^{n}\right|=0\right\}$ we have

$$
\left[X^{n}, X^{n}\right]=\left[M^{n}, M^{n}\right]+\left[B^{n}, B^{n}\right]+2\left[M^{n}, B^{n}\right]
$$

and

$$
\sup _{s \leqslant t}\left|\left[X^{n}, X^{n}\right]-\left[M^{n}, M^{n}\right]\right| \leqslant \operatorname{Var}\left(B^{n}\right)_{t} \sup _{s \leqslant t}\left(\left|\Delta B_{s}^{n}\right|+2\left|\Delta M_{s}^{n}\right|\right) .
$$

We know that $\operatorname{Var}\left(B^{n}\right)_{t}$ is tight. Let us first check that

$$
\sup _{s \leqslant t}\left|\Delta B_{s}^{n}\right| \stackrel{\mathbf{P}}{\longrightarrow} 0 \text {. }
$$


Observe that

$$
\left|\Delta B_{s}^{n}\right|=h(x) * \nu^{n}(\{s\}, d x) \leqslant \varepsilon+\Delta \mathbb{I}_{\{|x|>\varepsilon\}} * \nu_{s}^{n} \leqslant \varepsilon+\mathbb{I}_{\{|x|>\varepsilon\}} * \nu_{t}^{n}
$$

(assuming $h(x)=x$ on the set $\{|x|<\varepsilon\}$ and $|h(x)| \leqslant 1$ ). So

$$
\sup _{s \leqslant t}\left|\Delta B_{s}^{n}\right| \leqslant \varepsilon+\mathbb{I}_{\{|x|>\varepsilon\}} * \nu_{t}^{n}
$$

which yields $(2.2)$ in virtue of $\left[\delta-\mathbf{R}^{+}\right]$.

Let us then prove

$$
\sup _{s \leqslant t}\left|\Delta M_{s}^{n}\right| \stackrel{\mathbf{P}}{\longrightarrow} 0 .
$$

We have

$$
\Delta M_{s}^{n}=\Delta X_{s}^{n}-\Delta B_{s}^{n}-\Delta \check{X}(h)_{s}=h\left(\Delta X_{s}^{n}\right)-\Delta B_{s}^{n},
$$

so, as $|h(x)| \leqslant|x|$,

$$
\left|\Delta M_{s}^{n}\right| \leqslant\left|\Delta X_{s}^{n}\right|+\left|\Delta B_{s}^{n}\right|
$$

and (2.3) follows.

Thus, we have then proved that:

$$
\sup _{s \leqslant t}\left|\left[X^{n}, X^{n}\right]-\left[M^{n}, M^{n}\right]\right| \stackrel{\mathbf{P}}{\longrightarrow} 0
$$

and, as Corollary 1 gives $\left[X^{n}, X^{n}\right]_{t} \stackrel{\mathbf{P}}{\longrightarrow} C_{t}$, we obtain $\left[M^{n}, M^{n}\right]_{t} \stackrel{\mathbf{P}}{\longrightarrow} C_{t}$. Now $\left[\gamma-\mathbb{R}^{+}\right]$ follows from a standard argument given in [5] that establishes, that under (2.1)

$$
\sup _{s \leqslant t}\left|\left\langle M^{n}, M^{n}\right\rangle-\left[M^{n}, M^{n}\right]\right| \stackrel{\mathbf{P}}{\longrightarrow} 0 .
$$

$\mathrm{Pr}$ o of of $\mathrm{C}$ or oll a r y 2. Let us first take a truncation function $h$ that satisfies $h(x)=x$ for $|x| \leqslant c$ : we then have $B^{n}(h)=0$.

$(1) \Rightarrow(2)$ is a particular case of Corollary 1.

(3) $\Rightarrow(1)$ is a particular case of Feigin's Theorem (1985), see also [2, Section VIII.5.42].

(2) $\Rightarrow$ (3). Since (2.1) $\forall t \in \mathbf{R}^{+}$is equivalent to $\left[\delta-\mathbf{R}^{+}\right]$and under (2.1) convergence (2.4) takes place, it is enough to prove that $(2) \Rightarrow(2.1)$.

Now it follows from (2) that

$$
\sup _{s \leqslant t}\left|\Delta\left[X^{n}, X^{n}\right]_{s}\right| \stackrel{P}{\longrightarrow} 0 .
$$

Since $\left|\Delta X^{n}\right|^{2}=\sum_{\imath=1}^{d} \Delta\left[X^{n, \imath}, X^{n, \imath}\right],(2.1)$ holds.

Acknowledgements. The author is indebted to A. N. Shiryaev, D. O. Kramkov, and A. A. Gushchin for helpful discussions.

\section{REFERENCES}

1. Feigin P. D. Stable convergence of semimartingales. - Stoch. Process. Appl., 1985, v. 19 , p. $125-134$.

2. Jacod J., Shiryaev A. N. Limit Theorems for Stochastic Processes. Berlin, Heidelberg: Springer-Verlag, 1987.

3. Липчер P. ШІ., Ширяев $A$. Н. Слабая сходимость последовательности семимартингалов к процессу диффузионного типа. - Матем. сб., 1983, т. 121 (163), № 2, c. $176-200$.

4. Мордески Э. Необходимые условия устойчивой сходимости семимартингалов. Успехи матем. наук., 1993, т. 48, № 2, с. 193-194.

5. Rebolledo R. Central limit theorems for local martingales. - Z. Wahrscheinlichkeitstheor. verw. Geb., 1980, v. 51, p. 269-286. 